\title{
ANÁLISE DE POLÍTICAS DE INFORMAÇÃO EM REPOSITÓRIOS INSTITUCIONAIS: Bases para a gestão de acervos audiovisuais
}

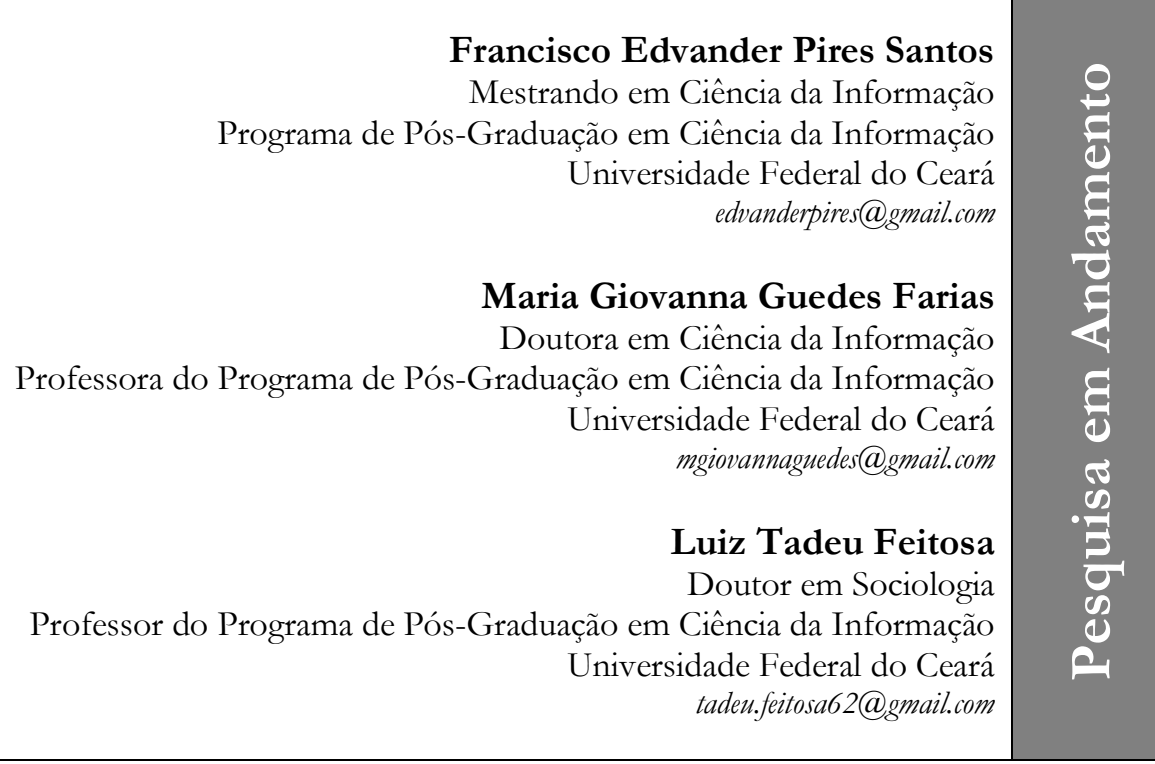

\section{Resumo}

Analisa, comparativamente, a estrutura de dez repositórios digitais de universidades federais e centros de pesquisa brasileiros, visando identificar se há política de informação e se esta contempla a gestão de acervos audiovisuais. Apresenta uma análise das políticas, resoluções e portarias que regulamentam os dez repositórios institucionais selecionados para este estudo sob o critério de maior destaque no site Ranking Web of Repositories. Discute os conceitos de acesso aberto e repositório digital à luz da literatura em Biblioteconomia e Ciência da Informação. Apresenta os tipos de coleções audiovisuais que podem constar na estrutura de um repositório institucional customizado no software DSpace, considerando as categorias definidas a partir da análise dos repositórios e das políticas de informação, a saber: acervo cinematográfico, televisivo, sonoro, instrucional, eventos, artístico e cultural. Conclui que, para a incorporação de coleções audiovisuais, a estrutura rígida dos repositórios institucionais deve ceder lugar à estrutura flexível, e que as principais decisões precisam ser documentadas numa política de informação.

\section{Palavras-chave}

Política de informação. Repositório institucional. Repositório digital. Acervo audiovisual. Acesso aberto.

\section{INTRODUÇÃO}

A gestão da informação audiovisual tornou-se imprescindível nas Instituições de Ensino Superior (IES). Mais especificamente em universidades federais brasileiras, é necessário que se formulem estratégias para que o bibliotecário também atue com essa demanda informacional. Aliadas à atuação e mediação do bibliotecário estão as ferramentas e técnicas de gestão mais recomendadas para a incorporação dos acervos audiovisuais ao cotidiano de bibliotecas universitárias, ou mesmo à criação de um centro de documen- tação audiovisual na universidade. Entendemos que uma dessas ferramentas são os repositórios digitais, denominados repositórios institucionais quando implantados por uma instituição, no sentido de haver resoluções, portarias ou políticas que norteiam os objetivos, as responsabilidades e os tipos de material aceitos para submissão.

Partindo desse cenário, o objetivo desta investigação é apresentar um comparativo de políticas de informação e repositórios institucionais de universidades federais e centros de pesquisa brasileiros no que se refere à incorporação e disponibilização de 
material audiovisual. Além disso, este artigo se constitui como uma das etapas metodológicas de uma pesquisa de mestrado, a qual visa desenvolver uma política de informação para a gestão de acervos audiovisuais.

Para tanto, recorremos aos seguintes métodos: pesquisa bibliográfica sobre acesso aberto e repositórios digitais; análise da estrutura de 10 repositórios institucionais de universidades e institutos de pesquisa no Brasil; análise da política de informação de cada um dos 10 repositórios selecionados; e construção de um mapa conceitual que embasa o desenvolvimento de uma política de informação para a gestão de acervos audiovisuais em repositório digital. Nesse sentido, serão apresentados os tipos de coleções que podem compor a estrutura de um repositório audiovisual por meio do software DSpace. Desse modo, a análise das políticas de informação foi complementada com uma categorização inicial das coleções definidas, baseadas na produção audiovisual de uma universidade pública brasileira.

\section{ACESSO ABERTO E REPOSITÓ- RIOS DIGITAIS}

O movimento pelo acesso aberto à produção técnico-científica ganhou impulso no Brasil no início dos anos 2000. Dentre as vantagens e benefícios do livre acesso à produção científica, tem-se o fato de que as universidades e os institutos de pesquisa passaram a ser instituições disseminadoras de sua própria produção, o que antes era condicionado a editoras e aos periódicos especializados com os quais se mantinham convênios por meio de assinaturas, que representavam uma grande despesa institucional.

Essa mudança de paradigma possibilitou às bibliotecas atuarem nesse novo cenário, no sentido amplo do termo "gestão da informação", ou seja, desde a produção, perpassando pelo autoarquivamento, submissão, disponibilização, disseminação, uso, até a análise das estatísticas de acesso aos documentos. Assim, emergiram os repositórios digitais, que se tornam institucionais a partir do momento de sua implantação nu- ma IES ou num órgão de pesquisa. De acordo com Mardero Arellano (2009), o que determina o tipo de repositório digital são a aplicação e os objetivos a que se destina e qual a ferramenta tecnológica a ser adotada. Diante disso, os repositórios podem ser classificados como:

a) Temáticos: voltados para uma área específica do conhecimento;

b) Institucionais: abrigam arquivos variados, desde que sejam produções acadêmicas respaldadas por uma instituição. Além disso, devem ser acessíveis aos usuários, interoperáveis e garantir a preservação digital de seus materiais a longo prazo.

$\mathrm{Na}$ definição de Marcondes e Sayão (2009, p. 9),

Um repositório institucional é uma biblioteca digital destinada a guardar, preservar e garantir livre acesso, via internet, à produção científica no âmbito de uma dada instituição.

Contudo, esse conceito se expande para além do livre acesso à produção científica, pois também fazem parte do ambiente acadêmico as produções de conteúdo artístico e cultural, que nem sempre se caracterizam como produção técnico-científica.

Exemplos dessas produções são os acervos audiovisuais, constituídos por documentos que trazem informação textual, sonora e imagética de maneira sincronizada.

\footnotetext{
Por suas características, os documentos audiovisuais não são percebidos diretamente - precisam ser mediados por um aparato tecnológico e seu conteúdo tem uma duração linear: é percebido no tempo." (EDMONDSON, 2017, p. vii, grifo nosso).
}

Dentre esse aparato, temos os repositórios digitais, onde a informação audiovisual também pode ser disponibilizada segundo a filosofia do acesso aberto.

No que tange às políticas de informação que norteiam a gestão dos repositórios institucionais, Tomaél e Silva (2007, p. 4) destacam que "uma política de informação cobre os objetivos, diretrizes, práticas e intenções organizacionais que servem para fortalecer as decisões locais." As autoras 
afirmam, ainda, que numa política de informação devem constar: as designações de responsabilidade (criação, implementação e manutenção do repositório); os conteúdos aceitos para submissão; aspectos legais e licenças adotadas; padrões; diretrizes para preservação digital; níveis de acesso e uso; sustentabilidade e financiamento.

Por sua vez, Costa e Leite (2017, p. 140) entendem as políticas como sendo "os documentos que regulamentam diversos aspectos relacionados à existência e ao funcionamento dos RIs." Os autores discutem, considerando os repositórios selecionados em nível de América Latina, as políticas de funcionamento; políticas institucionais de informação; políticas de preservação de conteúdo; e políticas de direitos autorais.

Para que a memória institucional não se perca em meio ao universo de informação produzido atualmente, a implementação de repositórios digitais possibilita às instituições a garantia de que a informação será gerida desde a etapa de produção até o acesso do público na Internet. Faz parte da competência do bibliotecário atuar nessa vertente, cumprindo o seu papel de mediador dentro da instituição, ao promover essa ferramenta de disseminação e uso da informação produzida nas universidades e nos institutos de pesquisa. Constitui-se em grande desafio a implementação de um repositório digital, mas, se já implantado, o desafio muda para o delineamento de critérios, diretrizes e estratégias para o povoamento do repositório com novos tipos de coleções, corroborando o exposto por Dodebei (2009, p. 101):

Parece que as instituições devem começar a desenvolver, com urgência, políticas de seleção das informações que farão parte de seus repositórios institucionais e bibliotecas digitais.

Portanto, reunir e disseminar toda a produção da universidade é o papel primordial de um repositório institucional, cabendo ao bibliotecário atuar como protagonista nesse cenário e na escolha da abordagem para a política de informação e para a estrutura do sistema: se rígida, "ao priorizar conteúdos que foram submetidos ao processo de avaliação pelos pares", ou flexível, que "contempla, além da literatura científica avaliada por pares, outros conteúdos de natureza acadêmico-científica produzidos por membros da instituição.” (COSTA; LEITE, 2009, p. 173-174).

Dentre o conteúdo aplicável à abordagem flexível, encontram-se as coleções audiovisuais, que demandam conhecimentos, habilidades e atitudes por parte do bibliotecário, para que haja uma gestão adequada e eficaz desse tipo de informação. Durante muito tempo, foi possível constatar que os acervos audiovisuais eram geridos mediante uma "sub-rotina" em bibliotecas, arquivos e museus (SMIT, 1993); no entanto, ferramentas como os repositórios digitais permitem a incorporação desse tipo de material, que deve ser devidamente subsidiada por políticas de informação e por uma estrutura hierárquica, baseada em comunidades, subcomunidades e coleções, que contemplem, de fato, as peculiaridades de arquivamento, disseminação, preservação, acesso e uso da produção audiovisual.

\section{PERCURSO METODOLÓGICO}

Procedemos com a análise comparativa entre as políticas de informação de 10 repositórios institucionais de universidades federais brasileiras e de institutos de pesquisa, visando identificar se esses documentos normativos contemplam acervos audiovisuais no escopo da política. A análise ocorreu de abril a novembro de 2017, e a estrutura dos repositórios também foi levada em consideração.

Para a escolha dos repositórios analisados, recorremos ao critério de seleção daqueles que mais se destacaram em pesquisa realizada no Ranking Web of Repositories, cujo objetivo do site é promover as iniciativas de acesso aberto às publicações científicas por meio de indicadores usados para mensurar a visibilidade global e o impacto alcançado pelos repositórios digitais. Definimos a busca por repositórios institucionais da América Latina e, destes, selecionamos os mais acessados no Brasil, considerando o recorte temporal escolhido, cujas informações recu- 
peradas na pesquisa estão ilustradas na Figu-

ra 1.

Figura 1 - Ranking dos repositórios institucionais na América Latina

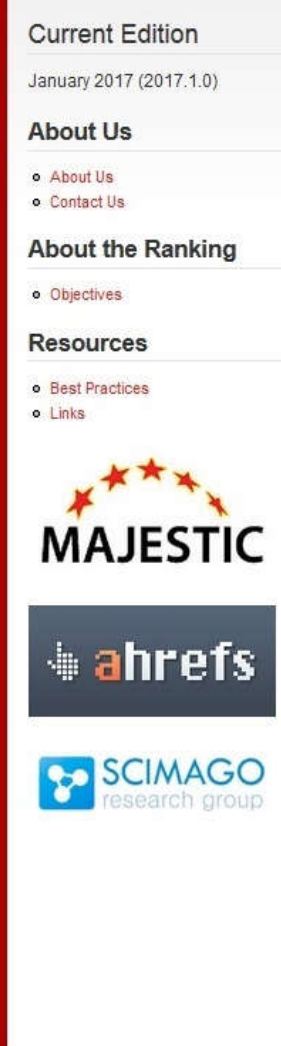

\begin{tabular}{|c|c|c|c|c|c|c|c|}
\hline \multicolumn{8}{|c|}{ Latin America } \\
\hline ranking & $\begin{array}{l}\text { World } \\
\text { Rank }\end{array}$ & Instituto & Country & $\underline{\text { Size }}$ & Visibility & $\begin{array}{l}\text { Files } \\
\text { Rich }\end{array}$ & scholar \\
\hline 1 & 17 & $\begin{array}{l}\text { Universidade de São Paulo Biblioteca Diqital de Teses e } \\
\text { Dissertaç̃es }\end{array}$ & $\mathrm{ter}$ & 129 & 43 & 34 & 13 \\
\hline 2 & 42 & $\begin{array}{l}\text { Repositório Diqital Universidade Federal do Rio Grande do } \\
\text { Sul LUME }\end{array}$ & tot & 25 & 149 & 57 & 15 \\
\hline 3 & 47 & Repositório Digital Fundação Getulio Vargas & ter & 5 & 130 & 163 & 32 \\
\hline 4 & 60 & $\begin{array}{l}\text { Universidad de los Andes (Venezuela) Repositorio } \\
\text { Institucional }\end{array}$ & $\mathbf{m}$ & 229 & 66 & 48 & 147 \\
\hline 5 & 78 & $\begin{array}{l}\text { Servicio de Difusión de la Creación Intelectual Universidad } \\
\text { Nacional de la Plata }\end{array}$ & 포 & 76 & 236 & 66 & 34 \\
\hline 6 & 96 & Universidad Nacional de Colombia Repositorio Institucional & - & 287 & 247 & 69 & 64 \\
\hline 7 & 118 & Repositorio Académico de la Universidad de Chile & the & 86 & 284 & 235 & 95 \\
\hline 8 & 125 & $\begin{array}{l}\text { Repositório Institucional Universidade Federal de Santa } \\
\text { Catarina }\end{array}$ & $\mathrm{kg}$ & 63 & 451 & 233 & 27 \\
\hline 9 & 162 & $\begin{array}{l}\text { Repositório Institucional UNESP Universidade Estadual } \\
\text { Paulista Jútio de Mesquita Filho }\end{array}$ & tet & 46 & 575 & 326 & 19 \\
\hline 10 & 181 & Universidade de Brasilia Repository & tet & 191 & 411 & 247 & 110 \\
\hline 11 & 258 & Universidade Federal da Bahia Repositorio Institucional & $\mathbf{k g}$ & 92 & 523 & 256 & 172 \\
\hline 12 & 287 & Repositorio Escuela Superior Politécnica del Litoral & $=$ & 130 & 584 & 279 & 156 \\
\hline 13 & 322 & $\begin{array}{l}\text { Repositório Digital Institucional da Universidade Federal do } \\
\text { Paraná }\end{array}$ & 어 & 9 & 652 & 1043 & 156 \\
\hline 14 & 351 & Repositorio Institucional Universidad de Cuenca & $=$ & 227 & 779 & 473 & 67 \\
\hline 15 & 359 & Universidad del Rosario Repositorio Institucional EdocuR & - & 74 & 642 & 339 & 287 \\
\hline 16 & 381 & Repositorio Universidad Politécnica Salesiana & $=$ & 188 & 720 & 407 & 160 \\
\hline 17 & 407 & Maxwell Pontificia Universidade Católica do Rio de Janeiro & ter & 305 & 429 & 443 & 675 \\
\hline 18 & 470 & Repositorio Institucional Universidade Fe deral do Ceará & Ex & 250 & 933 & 552 & 122 \\
\hline
\end{tabular}

Fonte: Ranking Web of Repositories. Disponível em: http:/ / repositories.webometrics.info. Acesso em: 17 abr. 2017.

Da lista recuperada na pesquisa, elegemos para análise 10 dos repositórios de instituições brasileiras que mais se destacaram no ranking, quais sejam: Fundação Getúlio Vargas (FGV); Fundação Oswaldo Cruz (FIOCRUZ); Instituto Brasileiro de Informação em Ciência e Tecnologia (IBICT); Universidade de Brasília (UnB); Universidade Estadual Paulista (UNESP); Universidade Federal do Rio Grande do Norte (UFRN); Universidade Federal do Ceará (UFC); Universidade Federal da Bahia (UFBA); Universidade Federal do Paraná (UFPR); e Universidade Federal do Rio Grande do Sul (UFRGS).

Após a seleção, observamos se o repositório possui política, portaria, resolução, orientações ou mesmo outro documento normativo que norteie os trabalhos de gestão da informação e de submissão de material, bem como se a estrutura do repositório contempla a incorporação de acervos audiovisuais e, em caso positivo, quais os tipos de material e de que forma essa submissão é realizada. Desse modo, foi possível elaborar um quadro composto pelo nome da instituição, link de acesso ao repositório, especificação se há ou não uma política e, por fim, se a informação audiovisual está contemplada nos repositórios analisados, conforme demonstra o Quadro 1.

Para chegarmos à construção desse quadro, analisamos cada documento normativo e a estrutura de cada repositório institucional. $\mathrm{O}$ detalhamento dessa análise será abordado na próxima seção. 
Quadro 1 - Comparativo entre os repositórios institucionais analisados

\begin{tabular}{|c|c|c|c|c|c|}
\hline \multicolumn{6}{|c|}{ REPOSITÓRIOS INSTITUCIONAIS ANALISADOS } \\
\hline Instituição & Link de acesso & $\begin{array}{c}\text { Política de } \\
\text { informação? }\end{array}$ & $\begin{array}{c}\text { Nomenclatura } \\
\text { da política }\end{array}$ & $\begin{array}{r}\text { Informação } \\
\text { audiovisual? }\end{array}$ & $\begin{array}{l}\text { Tipo de acervo } \\
\text { audiovisual } \\
\end{array}$ \\
\hline FGV & $\begin{array}{c}\text { http://bibliotecadigital.fgv.br/d } \\
\text { space/ }\end{array}$ & Não identificada & - & $\operatorname{Sim}$ & $\begin{array}{l}\text { Entrevistas em } \\
\text { áudio e vídeo } \\
\text { veiculadas pela } \\
\text { grande mídia }\end{array}$ \\
\hline FIOCRUZ & https://www.arca.fiocruz.br/ & $\operatorname{Sim}$ & $\begin{array}{l}\text { Política de aces- } \\
\text { so aberto ao } \\
\text { conhecimento }\end{array}$ & $\operatorname{Sim}$ & $\begin{array}{c}\text { Videoaulas; } \\
\text { Palestras; } \\
\text { Documentários; } \\
\text { Vídeos institucio- } \\
\text { nais }\end{array}$ \\
\hline IBICT & http://repositorio.ibict.br/ & $\operatorname{Sim}$ & $\begin{array}{l}\text { Portaria, política } \\
\text { de indexação e } \\
\text { guia de depósito }\end{array}$ & Não & $\begin{array}{l}\text { Porém, link remis- } \\
\text { sivo ao canal no } \\
\text { YouTube }\end{array}$ \\
\hline UnB & http://repositorio.unb.br/ & Sim & $\begin{array}{l}\text { Resolução, } \\
\text { portarias e carti- } \\
\text { lha Creative } \\
\text { Commons }\end{array}$ & Não & - \\
\hline UNESP & https://repositorio.unesp.br/ & $\operatorname{Sim}$ & $\begin{array}{l}\text { Política de ges- } \\
\text { tão / regulamen- } \\
\text { to interno }\end{array}$ & $\operatorname{Sim}$ & Podcast \\
\hline UFRN & $\begin{array}{c}\text { https://repositorio.ufrn.br/jspu } \\
\text { i/ }\end{array}$ & Sim & Resolução & Não & - \\
\hline UFC & http://www.repositorio.ufc.br/ & $\operatorname{Sim}$ & Resolução & Não & - \\
\hline UFBA & https://repositorio.ufba.br/ri/ & $\operatorname{Sim}$ & $\begin{array}{l}\text { Portaria e orien- } \\
\text { tações para uso }\end{array}$ & $\operatorname{Sim}$ & $\begin{array}{c}\text { Programa de rádio } \\
\text { e TV }\end{array}$ \\
\hline UFPR & http://acervodigital.ufpr.br/ & Não identificada & - & $\operatorname{Sim}$ & $\begin{array}{l}\text { Programa de TV, } \\
\text { entrevistas, pales- } \\
\text { tras e tutoriais }\end{array}$ \\
\hline UFRGS & http://www.lume.ufrgs.br/ & $\operatorname{Sim}$ & $\begin{array}{l}\text { Portaria, instru- } \\
\text { ção normativa, } \\
\text { ofício circular e } \\
\text { resolução }\end{array}$ & $\operatorname{Sim}$ & $\begin{array}{c}\text { Programa de rádio } \\
\text { e TV }\end{array}$ \\
\hline
\end{tabular}

Fonte: Elaborado pelos autores com base nos dados da pesquisa (2017).

\section{ANÁLISE DAS POLÍTICAS E DOS REPOSITÓRIOS}

A partir da tela inicial dos repositórios institucionais selecionados, os documentos normativos, identificados em forma de política, portaria, resolução e orientações, encontravam-se no topo da página, muitos deles acompanhados de termos de autorização para submissão de material ou de guias, ofícios e anexos que complementavam as diretrizes de acesso e uso do repositório. A estrutura de comunidades, subcomunidades e coleções 
variou de acordo com a instituição, na medida em que houve distinção na configuração da interface de cada repositório devido à customização permitida pelo software DSpace.

Ao navegar pelo Repositório Digital FGV, selecionamos a opção de busca por tipo de documento. Nela constatamos que há reportagens e entrevistas em áudio e vídeo, muitas delas produzidas e veiculadas pela Rádio CBN, Rádio Band News e TV Brasil. Com base nessa análise, inferimos que o critério de incorporação do material audiovisual ao repositório é o de participação de professores, pesquisadores ou algum outro membro da comunidade FGV nos programas e nas reportagens exibidas pela grande mídia. Além disso, matérias que falam sobre eventos promovidos pela instituição também são submetidas ao repositório. Não identificamos política de informação.

O Arca, Repositório Institucional da FIOCRUZ, possui a "política de acesso aberto ao conhecimento", instituída por meio de uma portaria. Em sua estrutura, a política define os objetivos e princípios do Arca, as responsabilidades pela gestão do repositório, as diretrizes para $\mathrm{O}$ autoarquivamento e assinala os direitos e deveres dos autores. No que se refere à informação audiovisual, há vídeos como coleções ao longo das comunidades e subcomunidades, com acervos de videoaulas, palestras, documentários e produções institucionais submetidas ao repositório.

$\mathrm{O}$ Repositório Institucional do IBICT traz uma política de informação respaldada por portaria e mais dois documentos normativos como diferencial: a política de indexação e o guia de depósito de obras. Porém, não identificamos produção audiovisual na estrutura do repositório, bem como não há menção a esse tipo de material nos documentos supracitados. Contudo, o repositório direciona o visitante para um canal no YouTube: o Acesso Aberto Brasil, o que se constitui em remissiva para a produção audiovisual da instituição ou de instituições afins que abordem a temática em questão.
Ao analisar o Repositório Institucional da UnB, deparamo-nos com diferentes documentos normativos e de orientação para o pesquisador que deseja submeter a sua produção. A política de informação, por exemplo, é regulamentada por uma resolução, que incentiva os autores a realizarem o depósito de artigos científicos que sigam a filosofia do acesso aberto. Além da política, há uma cartilha sobre as licenças Creative Commons e termos de autorização para publicação parcial. Não identificamos acervos audiovisuais nessa análise.

A política de gestão do Repositório Institucional da UNESP apresenta a missão do repositório e designa responsabilidades, atribuições, critérios para arquivamento, tipos de material e funções da coordenação executiva. Dentre os tipos de material aceitos para submissão, constam na política as gravações de som e de vídeo. $\mathrm{Na}$ estrutura do repositório, existe uma coleção destinada a podcast, que traz em seu acervo entrevistas gravadas pela assessoria de comunicação e imprensa da universidade sobre lançamentos de publicações pela Editora UNESP. Para além dos tipos de material, o Repositório Institucional da UNESP se destaca devido a uma categorização intitulada "tipo de produção", subdividida em produção administrativa, artística, científica, comemorativa, técnica e repositório de dados. Isso demonstra a preocupação do comitê gestor em vincular as comunidades, subcomunidades e coleções ao tipo de produção correspondente, o que permite uma maior possibilidade de recuperação da informação e de identificação e acesso ao acervo audiovisual.

O Repositório Institucional da UFRN mantém sua política de informação por meio de uma resolução. Nela estão estabelecidos as responsabilidades e os tipos de material passíveis de incorporação. Em sua estrutura, não identificamos informação audiovisual submetida. Similares à resolução da UFRN são as normas do Repositório Institucional da UFC, inclusive no que concerne aos tipos de material aceitos para submissão e às publicações desobrigadas de serem incorporadas. Tendo em vista a análise da 
estrutura de ambos os repositórios e de suas resoluções, percebemos que a abordagem rígida se sobressai devido aos tipos de documentos técnico-científicos que compõem as coleções.

No caso do Repositório Institucional da $U F B A$, a política de informação é regulamentada por portaria e há um documento normativo intitulado "Orientações para uso do repositório", no qual constam a missão, os objetivos, os tipos de produção aceitas para submissão, as responsabilidades, os direitos de uso, as diretrizes para a criação de comunidades, subcomunidades e coleções, bem como as políticas de submissão e de preservação. No documento, existe a divisão das produções a serem incorporadas, a saber: produção bibliográfica, técnica, cultural e trabalhos finais e parciais de curso. $\mathrm{Na}$ categoria "produção cultural", abrangem-se os programas de rádio e TV, sonoplastia, arranjos e composições musicais. Ao navegar pelo repositório, mais especificamente em "tipo de documento", constatamos que, dentre os acervos audiovisuais, há programas, reportagens e cobertura de eventos exibidos pela TV UFBA.

$\mathrm{Na}$ estrutura do Repositório Digital Institucional da UFPR, ao acessar os tipos de documento, há uma coleção audiovisual composta por entrevistas, palestras, tutoriais e vídeos instrucionais, além de uma coleção destinada exclusivamente à UFPR TV e à Rede IFES (sistema digital de permuta para programas de rádio e TV das universidades federais). No caso da UFPR TV, o acervo audiovisual é identificado pelo título ou assunto da matéria. Vale salientar que Sunye et al. (2009, p. 115) compartilham a experiência tanto sobre o fluxo da integração do acervo de vídeos quanto acerca da implantação do repositório digital na universidade. Além disso, até a data em que se deu a análise do repositório, consta no site do Sistema de Bibliotecas da UFPR que está em processo de construção a Biblioteca Digital de Imagem e Som, que, até então, remete-nos para o acervo audiovisual do repositório e também para o catálogo online. Especificamente sobre o catálogo online, realizamos uma pesquisa hipotética e constatamos que há acervo físico da UFPR TV em fitas MiniDV, cujo conteúdo encontra-se disponível também no repositório. Nessa análise, não identificamos política de informação.

De todos os repositórios analisados, o que mais se destaca na gestão audiovisual, em nossa concepção, é o Lume: Repositório Digital da UFRGS. Em sua política, regulamentada por portaria, estão descritos os objetivos, a inclusão de comunidades e coleções, as diretrizes para submissão, os padrões de metadados e aspectos sobre acesso, uso e licenças. Em "tipo de documento", há coleções de vídeos e podcasts, que apresentam reportagens, entrevistas e coberturas produzidas pela UFRGS TV e Rádio UFRGS. Tanto a TV quanto a Rádio são definidas como comunidades na estrutura do Lume, fazendo parte de suas subcomunidades os títulos dos programas ou quadros especiais que definem a matéria, tais como o "Acontece na UFRGS", "Meu Lugar na UFRGS", "Folhetim" etc. Para cada item da coleção, são atribuídos título, resumo, palavras-chave, duração, entrevistados, repórteres, editores, produtores, dentre outras indicações de responsabilidade. Nesse sentido, o diferencial do Lume está justamente na composição dos metadados específicos para a gestão da informação audiovisual em repositórios digitais, sendo, dessa forma, o que mais se aproxima de nossa proposta de pesquisa.

Conforme mencionamos anteriormente, este artigo é fruto de uma das etapas metodológicas de uma pesquisa de mestrado que visa desenvolver uma política de informação para gestão de acervos audiovisuais em repositório digital. Partimos, então, da análise de políticas de informação e construímos um mapa conceitual, baseado na publicação de Tomaél e Silva (2007), no qual especificamos as diretrizes para estruturação de um repositório institucional constituído por comunidades, subcomunidades e coleções audiovisuais, de acordo com a Figura 2. 
Figura 2 - Mapa conceitual para estruturação de repositório e política de informação audiovisual

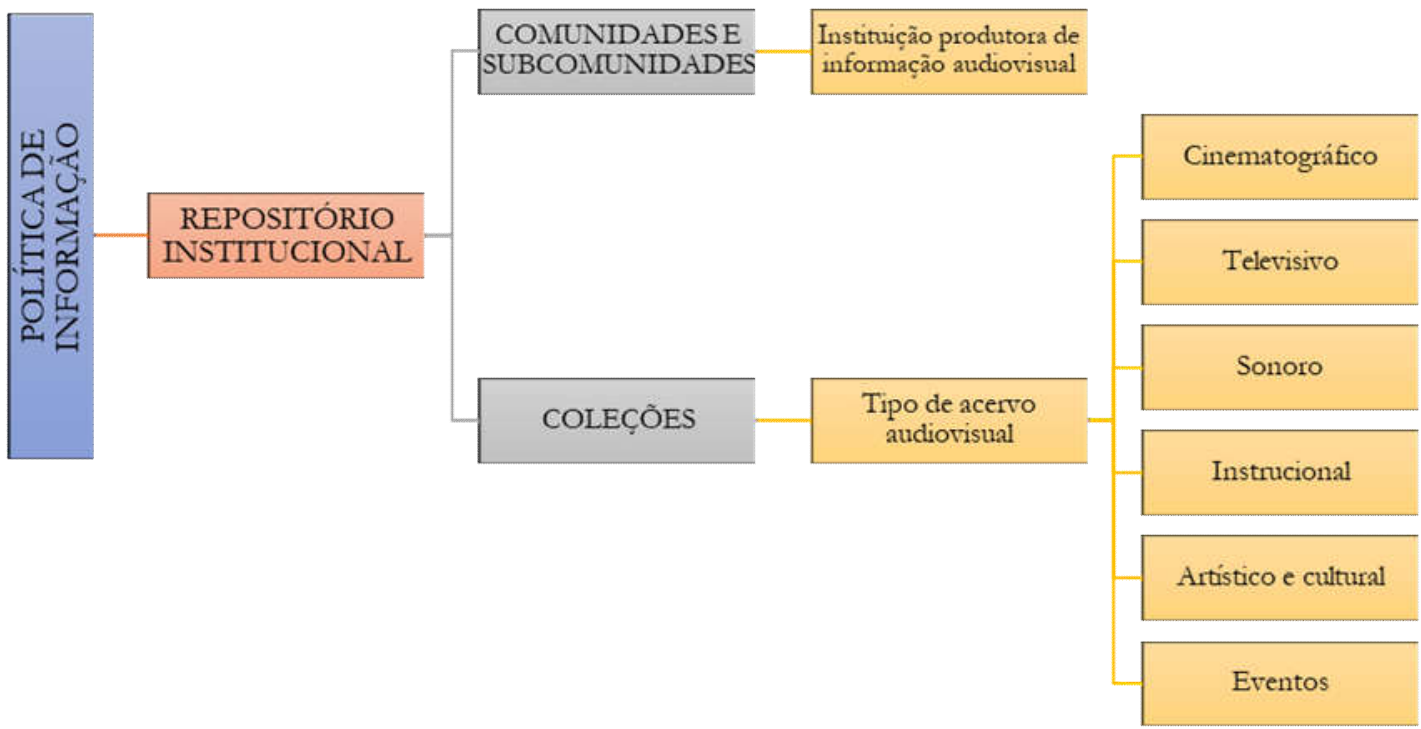

Fonte: Elaborado pelos autores (2017).

A partir da análise realizada, a qual embasará a elaboração de uma política de informação, percebemos a necessidade de estruturação de um repositório institucional exclusivamente para acervos audiovisuais. Esse repositório será constituído por: comunidades e subcomunidades, nas quais serão definidas as instituições produtoras de informação audiovisual no ambiente universitário; e coleções, que determinarão o tipo de acervo a ser incorporado, o qual é, por sua vez, categorizado como: cinematográfico, televisivo, sonoro, instrucional, artístico e cultural e de eventos. De fato, essa categorização vai ao encontro dos achados deste artigo.

Em nossa proposta inicial de pesquisa, a ramificação das coleções audiovisuais dar-se-á conforme os tipos de acervos preestabelecidos na Figura 3.

Figura 3 - Tipos de acervos audiovisuais para repositório institucional

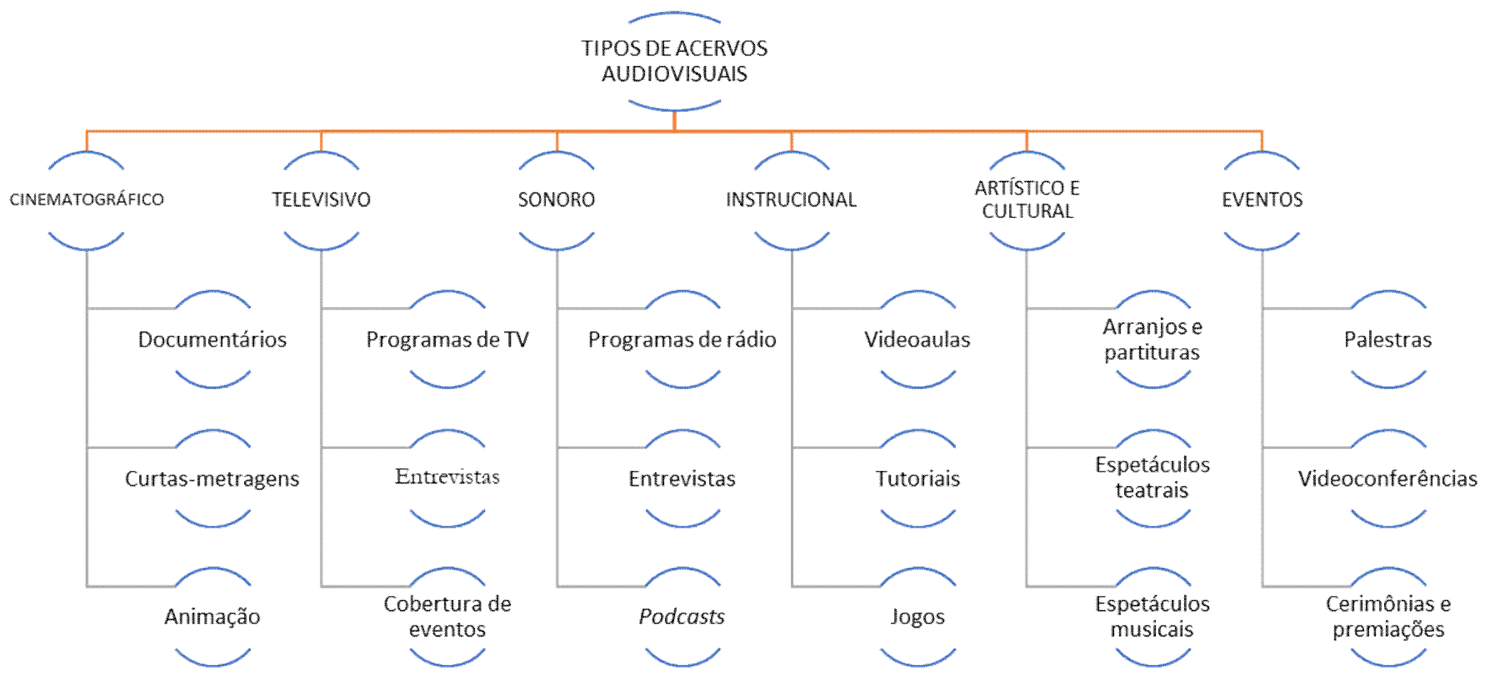

Fonte: Elaborado pelos autores (2017). 
Para cada tipo de material, há metadados específicos destinados à recuperação da informação. Citando como exemplo os acervos audiovisuais da figura acima, é preciso adequar ao DSpace um padrão de metadados que seja aplicável apenas a esses materiais. Nesse sentido, a indicação de responsabilidade no audiovisual vai além do nome de autor, orientador ou coorientador, por exemplo, pois partimos do pressuposto de que as pessoas envolvidas na produção das imagens denominam-se como produtores, repórteres, cinegrafistas, apresentadores, editores, entrevistados etc. Desse modo, um repositório digital, seja institucional ou temático, não pode ser pensado como uma estrutura rígida, já que a própria estrutura do DSpace permite a configuração de metadados de acordo com os tipos de documento depositados, ou seja, numa abordagem flexível.

Um dos fatores que devem ser pensados durante a elaboração de uma política de informação que contemple o audiovisual é o espaço de armazenamento em servidor, pois é fundamental pensar prospectivamente, tendo em vista os tamanhos e formatos de arquivos a serem submetidos. A compra de equipamentos, principalmente nas IES públicas, nem sempre atinge o resultado esperado, aliado à redução de gastos, então quando os gestores e a equipe de tecnologia da informação não se antecipam a questões sobre espaço de armazenamento, o trabalho de uma equipe e de uma comunidade poderá ser prejudicado no futuro, bem como a imagem do próprio repositório institucional.

\section{CONSIDERAÇÕES PARCIAIS}

A implantação de um repositório institucional ou temático utilizando o software DSpace possibilita certa maleabilidade em trabalhar com variados tipos de material, inclusive audiovisuais. Além de ser um indicador de qualidade, aumenta a visibilidade da instituição, é interoperável (utiliza os protocolos OAI-PMH e OAI-ORE), aberto, flexível e de acesso livre, mas também permite restringir o acesso a determinados itens em redes locais para usuários registrados ou para uma comunidade específica, no caso de políticas mais rígidas de informação.

No que concerne ao audiovisual, é recomendado que haja metadados específicos para cada tipo de acervo, o que é perfeitamente possível dependendo das características da coleção a ser incorporada ao repositório e da forma como a comunidade acadêmica requer esse tipo de informação. Seja qual for a decisão do comitê gestor, esses e outros aspectos relevantes devem constar na política.

A rigidez de uma política de informação e da estrutura de um repositório digital, casos com os quais nos deparamos ao analisar algumas das resoluções que estabelecem as normas para o repositório institucional, que não contemplam a submissão de acervos audiovisuais, constitui-se um entrave para a visibilidade da produção artística e cultural das respectivas universidades. A política, pensada e desenvolvida sob o contexto informacional de anos atrás, pode até ser rígida, dependendo do ponto de vista do comitê gestor, mas a estrutura do DSpace não o é. Entendemos que o caráter positivista dessas políticas deve dialogar com as necessidades informacionais das Ciências $\mathrm{Hu}-$ manas e das áreas afins, principalmente no que se referem às manifestações artísticas, políticas e culturais, refletidas nas produções acadêmicas do ambiente universitário.

Nesses casos, é preciso que haja uma negociação, e até mesmo uma exposição de motivos, na tentativa de convencer os gestores acerca da importância dos materiais que fogem às características dos tipos de documentos tradicionais. Toda a produção acadêmica, seja ela científica, técnica, cultural ou artística, deve constar em repositório digital, pois é a memória institucional de uma IES. Nesse sentido, outro fator a ser considerado numa política é satisfazer as demandas geradas ou trazidas pela própria comunidade universitária, o que contempla não apenas o texto, mas o visual, imagético, sonoro e as manifestações culturais e artísticas.

Por outro lado, deparamo-nos com políticas de informação e estruturas de repositórios flexíveis, que abrangem a produção acadêmica em sua completude. Programas 
de rádio e TV, podcasts, documentários, videoaulas, tutoriais, palestras e vídeos institucionais são alguns dos tipos de acervo audiovisual que mais se destacam. Entretanto, observamos que a mediação do bibliotecário se faz extremamente necessária para além da catalogação e indexação desse material no repositório, no intuito de fazer com que o conteúdo desses acervos chegue, de fato, ao público ao qual se destina, e todas essas estratégias também precisam estar devidamente documentadas numa política de gestão audiovisual.

Em muitas situações, a ausência de estratégias de marketing e a centralização no processo de comunicação interna dificultam a operacionalização e até mesmo a gestão dos trabalhos em repositório institucional. Assim, é importante constar na política que as tarefas precisam ser descentralizadas, pois cada comunidade que acessa o repositório tem a sua necessidade particular de informação. Como exemplo, nem sempre convém subdividir uma determinada comunidade segundo os departamentos da instituição, pois, em muitos casos, a necessidade dessa comunidade é que as suas coleções estejam organizadas por programas de pósgraduação. Da mesma forma, considerando os acervos audiovisuais, cada comunidade e subcomunidade terá necessidades de informação específicas ao predeterminar as suas coleções.

Os demais critérios, diretrizes e estratégias a serem especificados na política de informação, tais como padrões de metadados, indexação, autoarquivamento, preservação digital, acesso e uso, serão discutidos mais profundamente no produto final da pesquisa, que, certamente, irá expandir as possibilidades e constatações apresentadas neste trabalho. Como base de todo esse processo, defenderemos a mediação do bibliotecário não somente na elaboração da política, mas também na efetiva gestão do repositório e no cumprimento das ações a serem delineadas.

\title{
ANALYSIS OF INFORMATION POLICIES ON INSTITUTIONAL REPOSITORIES: Bases to manage audiovisual collections
}

\begin{abstract}
This paper presents a comparative analysis between ten digital repositories of federal universities in Brazil, focusing on verifying if there is an information policy to each one of them and if the policy has considered the management of audiovisual collections. It also presents an analysis based on each policy or other kind of normative document that regulates the institutional repositories chosen by considering the Ranking Web of Repositories. As a theoretical approach, some concepts of open access and digital repository are discussed from a short literature review on Library and Information Science. After that, some kind of audiovisual collections are presented as a proposal to be inserted in the structure of an institutional repository developed on DSpace, by considering the categories that were found from that analysis: academic cinema, television, sound, instructional videos, cultural and artistic productions and coverage of events. Finally, it concludes that the "soft" approach of digital repositories must be taken into consideration to manage audiovisual collections if compared to the "bard" one, as well as all decisions should be documented in an information policy.
\end{abstract}

Keywords

Information policy. Institutional repository. Digital repository. Audiovisual collection. Open Access. Artigo recebido em 13/07/2018 e aceito para publicação em 10/09/2018

\section{REFERÊNCIAS}

BARDIN, L. Análise de conteúdo. Tradução: Luís Antero Reto e Augusto Pinheiro. São Paulo: Edições 70, 2016.
COSTA, M. P.; LEITE, F. C. L. Repositórios institucionais da América Latina e o acesso aberto à informação científica. Brasília: Instituto Brasileiro de Informação em Ciência e Tecnologia, 2017. Disponível em:

http:/ /eprints.rclis.org/31109/1/Repositori 
O\%20America\%20Latina_Digital.pdf. Acesso em: 05 nov. 2017.

COSTA, S. M. S.; LEITE, F. C. L. Insumos conceituais e práticos para iniciativas de repositórios institucionais de acesso aberto à informação científica em bibliotecas de pesquisa. In: SAYÃO, L. et al. (Org.). Implantação e gestão de repositórios institucionais: políticas, memória, livre acesso e preservação. Salvador: EdUFBA, 2009. p. 163 202. Disponível em:

https://repositorio.ufba.br/ri/bitstream/uf ba/473/3/implantacao_repositorio_web.pdf . Acesso em: 30 abr. 2017.

DODEBEI, V. Repositórios institucionais: por uma memória criativa no ciberespaço. In: SAYÃO, L. et al. (Org.). Implantação e gestão de repositórios institucionais: políticas, memória, livre acesso e preservação. Salvador: EdUFBA, 2009. p. 83-106. Disponível em: https://repositorio.ufba.br/ri/bitstream/uf ba/473/3/implantacao_repositorio_web.pdf . Acesso em: 30 abr. 2017.

EDMONDSON, R. Arquivística audiovisual: filosofia e princípios. Tradução: Carlos Roberto Rodrigues de Souza. Brasilia: UNESCO, 2017. Disponível em: http://unesdoc.unesco.org/images/0025/00 2592/259258POR.pdf. Acesso em: 07 jan. 2018.

FUNDAÇÃO OSWALDO CRUZ. Política de acesso aberto ao conhecimento. 2014. Disponível em: https://portal.fiocruz.br/sites/portal.fiocruz .br/files/documentos/portaria__politica_de_acesso_aberto_ao_conhecimen to_na_fiocruz.pdf. Acesso em: 16 jun. 2017.

INSTITUTO BRASILEIRO DE INFORMAÇÃO EM CIÊNCIA E TECNOLOGIA. Portaria $\mathrm{n}^{\circ}$ 043, de 10 de setembro de 2014. Dispõe sobre a política para o repositório institucional da produção científica do IBICT. [Brasília], 2014. Disponível em: http:// repositorio.ibict.br/Pol\%C3\%ADtica $\% 20 \mathrm{de} \% 20$ Informa $\% \mathrm{C} 3 \% \mathrm{~A} 7 \% \mathrm{C} 3 \% \mathrm{~A} 3 \mathrm{o} \% 2$
0RI $\% 20 I B I C T \% 20-$

\%20Portaria \%20n\%C2\%BA\%20043.2014_2 014.pdf. Acesso em: 28 out. 2017.

MARCONDES, C. H.; SAYÃO, L. F. À guisa de introdução: repositórios institucionais e livre acesso. In: SAYÃO, L. et al.

(Org.). Implantação e gestão de repositórios institucionais: políticas, memória, livre acesso e preservação. Salvador: EdUFBA, 2009. p. 9-21. Disponível em: https://repositorio.ufba.br/ri/bitstream/uf ba/473/3/implantacao_repositorio_web.pdf . Acesso em: 30 abr. 2017.

MARDERO ARELLANO, M. A. Repositórios, Acesso Livre e Preservação Digital. 2009. Disponível em: https://pt.slideshare.net/gemireki/repositri os-acesso-livre-e-preservao-digital. Acesso em: 12 nov. 2017. Apresentação de slides.

RANKING WEB OF REPOSITORIES. [Busca pelo ranking de repositórios institucionais na América Latina]. Disponível em: http://repositories.webometrics.info. Acesso em: 17 abr. 2017.

SMIT, J. W. O documento audiovisual ou a proximidade entre as 3 Marias. Revista Brasileira de Biblioteconomia e Documentação, São Paulo, v. 26, n.1/2, p. 81-85, jan./jun. 1993.

SUNYE, M. et al. A experiência da UFPR na construção de repositórios digitais: a implantação integrada das ferramentas Dspace e Open Journal System. In: SAYÃO, L. et al. (Org.). Implantação e gestão de repositórios institucionais: políticas, memória, livre acesso e preservação. Salvador: EdUFBA, 2009. p. 107-122. Disponível em: https://repositorio.ufba.br/ri/bitstream/uf ba/473/3/implantacao_repositorio_web.pdf . Acesso em: 30 abr. 2017.

TOMAÉL, M. I.; SILVA, T. E. Repositórios institucionais: diretrizes para políticas de informação. In: ENCONTRO NACIONAL DE PESQUISA EM CIÊNCIA DA INFORMAÇÃO, 8., 2007, Salvador. Anais 
eletrônicos... Disponível em: http://www.enancib.ppgci.ufba.br/artigos/ GT5--142.pdf. Acesso em: 30 abr. 2017.

UNIVERSIDADE ESTADUAL PAULISTA. Política de gestão do Repositório Institucional da UNESP: regulamento interno. Aprovada em 08 de novembro de 2016. Disponível em:

https://repositorio.unesp.br/handle/11449/ 144653. Acesso em: 30 out. 2017.

UNIVERSIDADE DE BRASÍLIA. Resolução da Reitoria n ${ }^{\circ} 101 / 2013$. Regulamenta a política de informação do Repositório Institucional da UnB. Brasília, 2013. Disponível em:

http://repositorio.unb.br/documentos/Res olu-

cao_da_Politica_de_Informacao_do_RIUnB .pdf. Acesso em: 16 nov. 2017.

UNIVERSIDADE FEDERAL DA BAHIA. Orientações para uso do Repositório Institucional da UFBA. Disponível em: https://repositorio.ufba.br/ri/about/folder _repositorio_web.pdf. Acesso em: 17 nov. 2017.

UNIVERSIDADE FEDERAL DA BAHIA. Portaria n $\mathbf{n}^{\mathbf{0}}$ 24/2010. Salvador, 2010. Disponível em: https://repositorio.ufba.br/ri/about/politic $\mathrm{a} \% 20$ institucional.pdf. Acesso em: 17 nov. 2017.
UNIVERSIDADE FEDERAL DO CEARÁ. Resolução $\mathbf{n}^{\circ}$ 02/CONSUNI, de 29 de abril de 2011. Estabelece normas para a Política Institucional de Informação Técnico-Científica da Universidade Federal do Ceará (UFC) no que se refere ao seu Repositório Institucional (RI). Fortaleza, 2011. Disponível em: http://www.repositorio.ufc.br/sobre/UFC_ Consuni_2011_Resolucao02.pdf. Acesso em: 25 abr. 2017.

UNIVERSIDADE FEDERAL DO RIO GRANDE DO NORTE. Resolução $\mathbf{n}^{\mathbf{0}}$ 059/2010-CONSEPE, de 13 de abril de 2010. Estabelece normas para a Política Institucional de Informação Técnico-Científica da Universidade Federal do Rio Grande do Norte (UFRN) no que se refere ao seu Repositório Institucional (RI). Natal, 2010. Disponível em: http://repositorio.ufrn.br:8080/jspui/docu mentos/resolucao_592010_consepe_riufrn.pdf. Acesso em: 25 abr. 2017.

\section{UNIVERSIDADE FEDERAL DO RIO} GRANDE DO SUL. Portaria $\mathbf{n}^{\circ}$ 5068, de 13 de outubro de 2010. Institui a política institucional de informação para o Lume Repositório Digital da UFRGS. Disponível em:

http://www.lume.ufrgs.br/arquivos_downlo ad/Portaria-5068.pdf. Acesso em: 17 nov. 2017. 